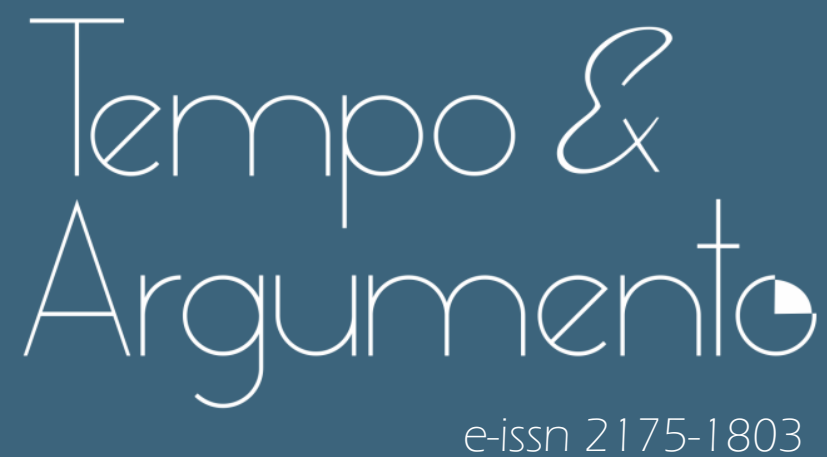

A batalha de Cuito Cuanavale 1987-1988: a guerra pela sua memória

\& Johny Santana de Araújo

Doutor em História Social pela Universidade Federal Fluminense (UFF).

Professor do Departamento de História, do Programa de Pós-Graduação

em História e do Programa de Pós-graduação em Ciência Política da

Universidade Federal do Piauí (UFPI).

Teresina, PI - BRASIL

lattes.cnpq.br/6182725298799980

johnysant@gmail.com

(1) orcid.org/0000-0003-3082-1785

Para citar este artigo:

ARAÚJO, Johny Santana de. A batalha de Cuito Cuanavale 1987-1988: a guerra pela sua memória. Tempo e Argumento, Florianópolis, v. 13, n. 32, e0 105, jan./abr. 2021

dof http://dx.doi.org/10.5965/2175180313322021 e0 105

Recebido: 30/10/2020

Aprovado: 19/03/2021 


\title{
A batalha de Cuito Cuanavale 1987-1988: A guerra pela sua memória
}

\begin{abstract}
Resumo
Em 1987, o governo do presidente José Eduardo dos Santos, de Angola, estava decidido por um termo nas operações da UNITA e da África do Sul no sudoeste africano. Auxiliadas por assessores militares russos, as FAPLA iniciaram uma grande ofensiva militar, mas, devido à inexperiência dos assessores e à rapidez da reação perpetrada pela UNITA auxiliada pela SADF, as forças combinadas angolanas recuaram até a pequena vila de Cuito Cuanavale. Após dias de cerco, o Exército Cubano interveio em favor da FAPLA revertendo, completamente, o desfecho da batalha que decidiu o futuro dos três países. Nesse sentido, o presente artigo pretende compreender como se deu o seu desfecho e como a memória em torno dela se tornou objeto de disputa entre os contendores.
\end{abstract}

Palavras-chave: Guerra Fria. Cuito Cuanavale. FAR. FAPLA. SADF. UNITA.

\section{The battle of Cuito Cuanavale (1987-1988): The war for its memory}

\begin{abstract}
In 1987, President's José Eduardo dos Santos government of Angola was committed to end UNITA and South Africa's operations in Southwest Africa. Assisted by Russian military advisers, FAPLA started a major military offensive and, due to the inexperience of advisers and the rapid reaction by UNITA and supported by SADF, the combined Angolan forces retreated to the small village of Cuito Cuanavale. After days of siege, the Cuban Army intervened in favor of FAPLA, completely reversing the outcome of the battle that decided the future of three countries. In this sense, the present article aims to understand how it ended and how the memory around it became the reason of dispute between the contenders.
\end{abstract}

Keywords: Cold War. Cuito Cuanavale. FAR. FAPLA. SADF. UNITA.

\section{Os antecedentes}

Quando Portugal deixou Angola em 1975, um longo processo de consolidação da formação do estado angolano foi ocorrendo. Não seria fácil, sobretudo pelas diferenças político-ideológicas entre antigos aliados, dentre os quais e mais significativo, Jonas Savimbi, e seu grupo, a União Nacional para a Independência Total de Angola, mais conhecido pelo acrônimo (UNITA). Uma luta 
aberta se iniciaria garantida pela aliança destes com os sul-africanos contra o regime comunista de Angola que havia se instalado.

Toda a arquitetura perpetrada pela Central Intelligence Agency (CIA) visando a derrubada do governo socialista de Angola, do presidente Antônio Agostinho Neto, contava com a disposição dos sul-africanos para executar, por procuração, o debacle de Angola como país." Mas, desde a luta pela independência que o presidente Agostinho Neto contava com o apoio da URSS e de Cuba. A União Soviética e outros países do Leste da Europa forneceram ao exército angolano Forças Armadas Populares de Libertação de Angola (FAPLA), armamento, assessores e pessoal técnico especializado. O exército cubano, após ajudar o Movimento Popular de Libertação de Angola (MPLA) a conquistar o poder, em 1975, considerou necessário permanecer no país até que as condições se estabilizassem a favor do presidente Agostinho Neto e do MPLA.

A UNITA recebeu apoio dos Estados Unidos - principalmente com equipamentos militares - para combater as forças das FAPLA. A África do Sul também forneceu à UNITA apoio militar através da realização de operações de combate transfronteiriças ocasionais do Sudoeste da África, atual Namíbia. ${ }^{2}$ Em 1966, Assembleia Geral da ONU determinou o término do mandato que a África do Sul detinha sobre a Namíbia. Ela havia sido estabelecida pela Liga das Nações Unidas e, após o fim da Primeira Guerra, a região fazia parte da antiga Colônia do Sudoeste Africano Alemão que, com a derrota alemã, havia passado ao controle sul-africano em 1919. No entanto, a África do Sul se recusou a reconhecer e continuou a governar o Sudoeste da África, isto é, a Namíbia.

Desde 1961, viu-se o início da resistência armada encabeçada pela Organização do Povo do Sudoeste Africano, em inglês: South West Africa People's Organization, (SWAPO) e seu braço armado, a People's Liberation Army of

\footnotetext{
'A Operação Savannah foi uma intervenção militar levada a cabo pelas Forças de Defesa da África do Sul em 1975-1976, ficou conhecida em Angola como Campanha de Invasão da África do Sul e Conquista de Luanda de 1975-1976. O resultado foi a vitória de Angola com ajuda de Cuba e da URSS. Sobre a operação, ver: (SPIES, 1989). Ver sobre a Operação Carlota desencadeada por Cuba para ajudar Angola em 1975, ver: SMITH, Wayne S. A trap in Angola. Foreign Policy, [s.l.], n. 62, p. 61-74, 1986.

2 Sobre a história militar contemporânea de Angola, ver: WEIGERT, Stephen L. Angola: a modern military history, 1961-2002. New York: Palgrave Macmillan, 2011.
} 
Namibia (PLAN), ${ }^{3}$ e as operações de contra insurgência sul-africanas. ${ }^{4}$ Após a independência de Angola, em 1975, a SWAPO ganhou o apoio do governo angolano para operar contra as forças sul-africanas. A preocupação estratégica do governo sul-africano passou a ser, portanto, garantir que a UNITA mantivesse a continuidade do controle sobre as regiões fronteiriças com a Namíbia, de modo a evitar que os guerrilheiros da SWAPO recebessem apoio angolano e ganhassem um trampolim no sul de Angola para lançar ataques contra o sudoeste da África. Sua estratégia de segurança foi moldada pelas doutrinas do intervencionismo preventivo e da guerra contrarrevolucionária.

Em agosto de 1981, a África do Sul lançou uma grande intervenção militar chamada de Operação Protea. Na sequência desta, a South African Defense Force (SADF) ocupou temporariamente $50.000 \mathrm{~km}^{2}$ da província do Cunene e a UNITA assumiu o controle administrativo efetivo da maior parte dessa região em janeiro de 1982 (SOUTH AFRICA, 1998, p. 42-61). Devido à insurgência da UNITA, o governo central de Angola nunca conseguiu obter o controle de todo o país, pois a UNITA controlava grande parte do sudeste de Angola. No entanto, sempre que era ameaçada, a África do Sul intervinha a seu favor, mantendo também toda a fronteira sul em Angola e, por vezes, partes da província do Cunene em ocupação, a partir da qual puderam realizar invasões e incursões constantes no país (SOUTH AFRICA, 1998, p. 42-61).

Neste artigo, apresentamos nuances de como se deu a batalha de Cuito Cuanavale, ocorrida no sul de Angola e próximo à fronteira com a Namíbia, entre 15 de novembro de 1987 e 23 de março de 1988. Essa batalha tem uma conotação simbólica e forte apelo nacionalista, tanto para angolanos quanto para sul-africanos, além de uma grande relevância para Cuba, tendo em vista que o país acabou marcando uma forte presença nas questões militares, políticas e de relações internacionais na África Austral. De modo que, ao tomar parte dela, acabou protagonizando o processo que consolidou a independência da Namíbia e levou ao fim o Apartheid na África do Sul.

\footnotetext{
${ }^{3}$ O nome pode ter sido adotado informalmente já em 1969.

${ }^{4}$ Sobre o processo ver: UDOGU, Emmanuel Ike. Liberating Namibia: the long diplomatic struggle between the United Nations and South Africa. Jefferson: Mcfarland, 2012.
} 
O texto ora escrito procura ainda avaliar como tem sido processada a disputa pela narrativa no campo historiográfico sobre a batalha, o seu desenvolvimento, o seu resultado, a sua escrita; com isso, busca demonstrar as dificuldades que alguns países têm em lidar com o seu passado, sobretudo as gerações mais antigas na África do Sul, que tomaram parte da guerra de fronteira, notadamente os antigos militares e combatentes da SADF, responsáveis pela condução de operações militares contra Angola. Questões que vão desde a aceitação da derrota militar à constatação da vitória angolana-cubana, e o fim da política racista no estado sul-africano.

\section{A última batalha da Guerra Fria na África}

Em meados de 1987, as FAPLA estavam se preparando para lançar mais uma ofensiva contra a UNITA. A operação se chamava Saudando outubro e estava sob a direção dos assessores russos. Ela fora planejada pelo tenente-general Pavel Gusev, com o comando do chefe do estado-maior, o general Ivan Ryabchenko (SHUBIN, 2007, p. 13). A maior parte do equipamento militar dos angolanos havia passado por reforço e atualização. Com a inclusão de novos armamentos, ${ }^{5}$ a operação representou a última iniciativa soviética para eliminar a UNITA na região de Mavinga e Jamba. Dentro do próprio território de Angola, foram gastos US \$ 1,5 bilhão em equipamento militar soviético, incluindo 150 tanques T-55 e T-62, helicópteros e artilharia pesada trazidos, com antecedência, para Angola (STAPLETON, 2010, p. 179).

Os sul-africanos estavam cientes da intensa preparação dos angolanos e do deslocamento de um grande contingente de tropas até a pequena cidade de Cuito Cuanavale, localizada entre Jamba e Mavinga, próximo da fronteira com a Namíbia. O governo Sul-africano tratou de alertar a UNITA e, em 15 de junho, iniciou secretamente o seu apoio em defesa de seu aliado na Namíbia (GEORGE, 2005, p. 201).

Tanto para a UNITA como para os sul-africanos, a cidade de Cuito Cuanavale passou a ter relevância estratégica. Para a UNITA, a posição constituía

${ }^{5}$ Helicópteros Mi-24, de ataque, além de helicópteros Mi-8 e Mi-17, de transporte. 
o centro de gravidade para a defesa das suas estruturas militares no Sul de Angola. A manutenção das suas bases e de sua logística, do centro de instrução e comando e do núcleo da direção política da UNITA, em Jamba, dependiam do controle da região. Por extensão, havia necessidade de manter a estrada Menongue a Mavinga, e as passagens sobre o rio Cuito.

Para a África do Sul era imprescindível que a UNITA mantivesse sob o seu controle a região de Cuito Cuanavale, evitando assim a intensificação para o interior dos respectivos territórios, da guerra de libertação da Namíbia e da África do Sul, conduzida pela SWAPO e pelo Congresso Nacional Africano, em inglês: African National Congress (ANC), respectivamente.

Para as FAPLA alcançarem a Jamba, a porta de entrada estratégica era a região de Cuito Cuanavale. O pequeno aeródromo que lá existia assegurava que o apoio logístico fosse efetuado por via aérea - uma vantagem que seria explorada por qualquer contendor que controlasse a região. Por isso, tendo em vista a importância estratégica da referida localidade para as partes em conflito, a batalha era inevitável (BERNARDINO, 2013, p. 338). Assim, quando se deu o início da ofensiva das FAPLA, os sul-africanos tinham consciência que o seu aliado na Namíbia não tinha capacidade de resistir a ela e, em 4 de agosto daquele ano, a SADF deu início a uma operação militar chamada de Moduler, tendo se engajado rapidamente nos combates sob o comando do coronel Jock Harris, o qual foi substituído em setembro pelo coronel Deon Ferreira.

As tropas das FAPLA atingiram a margem norte do rio Lomba, perto de Mavinga, em 28 de agosto de 1987, e já eram esperados pela SADF que operava dentro do território de Angola. A partir de uma série de combates acirrados entre 9 de setembro e 7 de outubro, os sul-africanos impediram as FAPLA de cruzar o rio, interrompendo a ofensiva dos angolanos. Com isso, as FAPLA sofreram pesadas perdas e os soviéticos retiraram seus assessores da ofensiva, deixando as FAPLA sem liderança sênior. Em 29 de setembro, a SADF lançou uma contraofensiva com o objetivo de destruir todas as forças das FAPLA a leste do rio Cuito. Em 3 de outubro, a SADF atacou e aniquilou um batalhão inteiro das FAPLA na margem sul do rio Lomba e, dois dias depois, as FAPLA começaram a recuar para Cuito Cuanavale (GEORGE, 2005, p. 206-208). 
Muitos assessores soviéticos, em vários níveis de comando e aconselhamento, permaneceram com as tropas angolanas, segundo as memórias de um jovem oficial russo - o Tenente Sênior chamado Anatoly Eduardovich Alekseevsky, que participou da ofensiva e da operação de recuo até Cuito Cuanavale. Ele sublinha ainda que,

[...] sofremos mais no caminho de volta. Houve ataques do batalhão da UNITA, o que controlou a nossa retirada. Eles viram que não havia muito equipamento e tudo mais sobrou, e entenderam que a brigada está escapando de um cerco. Eles atacaram não só à noite, mas também durante o dia. E houve alguns confrontos bastante pesados, a ponto de nossa guarda de flanco ser varrida. As tropas da UNITA quase alcançaram a linha onde os nossos guardas de flanco tinham estado, nós próprios fomos forçados a disparar de volta com fuzis de assalto. E, naturalmente, não havia trincheiras, pois a brigada estava em movimento. (SHUBIN, 2007, p. 30)

As unidades das FAPLA puseram-se em retirada, enquanto as forças da SADF e da UNITA iniciaram sua perseguição às forças angolanas. Em 14 de outubro, as tropas sul-africanas começaram o cerco a Cuito Cuanavale. No final de outubro, os sul-africanos já haviam se aproximado o suficiente do lugar para começar um forte e intenso bombardeio regular de artilharia, com canhões G5 de 155 mm de longo alcance contra a cidade (POLLACK, 2013, p. 162). O assédio foi intensificado com disparos a uma distância de 30 a $40 \mathrm{~km}$ a partir de pontos estratégicos.

Cuito Cuanavale era importante para as FAPLA porque havia uma base aérea avançada para patrulhar e defender o sul de Angola. Além disso, era igualmente considerada uma importante porta de entrada para o centro de comando da UNITA no Sudeste. Com os sul-africanos no contra-ataque, a cidade e a base, e possivelmente toda a região de Cuando Cubango ficaram sob ameaça. Quando Angola planejou a sua operação para o sul contra a UNITA, o presidente Fidel Castro havia dissuadido a sua realização tendo, inclusive, aconselhado o general Gusev a não se envolver "em ofensivas tão devastadoras, caras e por fim, inúteis" (CASTRO; RAMONET, 2006, p. 326). Em grande parte, os comandantes militares de Cuba discordavam dos seus colegas russos em relação a desafiar a UNITA e a África do Sul. 
Diante da ameaça às suas forças no Sul, o governo do presidente José Eduardo dos Santos solicitou, em 15 de novembro, em caráter de urgência, a assistência militar de Cuba. O presidente Fidel Castro aprovou, no mesmo dia, a intervenção das forças cubanas nomeando-a como Operação Maniobra XXXI Anniversario. Assim, as forças cubanas assumiram a iniciativa e o controle da situação (SANEY, 2006, p. 81-117). Tal como em 1975, Cuba despachou um grande contingente de tropas e armas através do Oceano Atlântico: 15.000 soldados e equipamentos, incluindo tanques, artilharia, armas antiaéreas e aeronaves. Fidel Castro não informou à URSS sobre sua decisão de intervir (VANNEMAN, 1990, p. 69-79). O presidente Castro concordou, com a condição de que ele e o general Arnaldo Ochoa recebessem o comando de todas as forças das FAPLA no front (CASTRO; RAMONET, 2006, p. 326-334).

Em meados de novembro, Castro assumiu o controle das operações angolanas e ordenou que 3.000 soldados cubanos, incluindo uma brigada blindada, unidades de artilharia autopropelida e aeronaves de combate defendessem Cuito Cuanavale e que os melhores pilotos de caça de Cuba fossem enviados a Angola. Na mesma época, as forças cubanas foram movidas para o sudoeste de Angola para ameaçar a fronteira com a Namíbia (STAPLETON, 2010, p. 182). Apesar de não ser responsável pela situação crítica das FAPLA, o governo de Cuba sentiu-se impelido a intervir para evitar um desastre total para as FAPLA. Segundo o juízo de Fidel Castro, se UNITA e a África do Sul obtivessem uma vitória, isso significaria a captura de Cuito e a destruição das melhores tropas das FAPLA.

No início de novembro, a SADF havia encurralado unidades das FAPLA em Cuito Cuanavale e estava prestes a destruí-las. Em 25 de novembro de 1987, o Conselho de Segurança da ONU exigiu a retirada incondicional da SADF de Angola até 10 de dezembro, mas os EUA garantiram que não haveria repercussões para a África do Sul. O secretário adjunto dos Estados Unidos para a África, Chester Crocker, garantiu ao embaixador de Pretória que: "A resolução não continha um apelo a sanções abrangentes e não previa qualquer assistência ao MPLA." Segundo Crocker, isso foi uma consequência dos esforços dos EUA para 
manterem a "resolução dentro dos limites." (CROCKER, 1987 apud GLEIJESES, 2013, p. 506).

Em dezembro, a situação para a FAPLA sitiada tornou-se crítica quando a SADF apertou o laço em torno do Cuito Cuanavale. Fontes militares sul-africanas e diplomatas ocidentais estavam confiantes de que a queda de Cuito era iminente (MWAKIKAGILE, p. 146). Contudo, os sul-africanos reuniram uma força de assalto de 10.000 soldados - suas próprias tropas e guerrilheiros da [...] UNITA. Com 300 tanques, carros blindados e 400 peças de artilharia, eles estavam tão confiantes na vitória que um porta-voz da UNITA em Washington anunciou, no final de janeiro, que seus homens estavam "parcialmente no controle" de Cuito Cuanavale (BROOKE, 1988, p.1). A partir de 21 de dezembro, os sul-africanos planejaram a operação final para desalojar as cinco brigadas das FAPLA que ainda estavam a leste do rio Cuito, "antes de se moverem para ocupar a cidade se as condições fossem favoráveis” (GEORGE, 2005, p. 214).

Em meados de janeiro de 1988, as primeiras forças cubanas já estavam em Cuito Cuanavale. A prioridade inicial do Exército de Cuba era salvar a posição, mas enquanto as forças se instalavam junto à guarnição angolana sitiada, eles fizeram preparativos para uma segunda frente em Lubango. Os cubanos manteriam uma frente sul Lubango-Menogue contra a UNITA para evitar que a SADF se aprofundasse em Angola (POLLACK, 2013, p. 175).

De meados de janeiro até o final de fevereiro, a SADF lançou seis grandes assaltos às posições das FAPLA a leste do rio Cuito, dos quais nenhum produziu resultados palpáveis. Embora o primeiro ataque, em 13 de janeiro de 1988, tenha sido bem-sucedido, significando quase um desastre para uma brigada das FAPLA, a SADF foi incapaz de continuar e recuou para suas posições iniciais.

Depois de um mês, a SADF estava pronta para o segundo ataque em 14 de fevereiro. Mais uma vez, retirou-se, mesmo após expulsar com sucesso as unidades cubanas e das FAPLA do terreno elevado de Chambinga. Escapando por pouco da catástrofe, as unidades das FAPLA a leste do rio Cuito recuaram para o triângulo Tumpo (rio), uma área menor, idealmente adequada para a defesa (POLLACK, 2013, p. 199). 
Em 19 de fevereiro, as SADF sofreram um primeiro grande revés quando um terceiro assalto contra um batalhão das FAPLA ao norte do rio Dala foi repelido. A SADF não conseguiu alcançar as posições avançadas das FAPLA e teve de se retirar. Nos dias seguintes, os cubanos intensificaram seus ataques aéreos contra as posições sul-africanas. Naquela época, o general Ochoa havia sido substituído pelo general Leopoldo Cintra Frias que assumiu o comando de todas as operações de defesa, se tornando comandante general de fato (POLLACK, 2013, p. 50).

Em 25 de fevereiro, as tropas da FAPLA e da Fuerzas Armadas Revolucionarias (FAR) repeliram um quarto ataque e as SADF tiveram de recuar para suas posições a leste do rio Tumpo. O fracasso desse ataque "provou ser um ponto de viragem na batalha de Cuito Cuanavale, aumentando o moral das FAPLA e paralisando o avanço sul-africano" (STAPLETON, 2010, p. 183). A quinta tentativa, em 29 de fevereiro, foi igualmente fracassada resultando na terceira derrota consecutiva da SADF. Depois de se recomporem e de mais alguma preparação, os sul-africanos lançaram seu último e quarto ataque malsucedido em 23 de março. Como escreveu o coronel Jan Breytenbach da SADF, o ataque sul-africano "foi paralisado de maneira opressiva e definitiva" pelas forças cubanas e das FAPLA combinadas. (BREYTENBACH, 2002, p. 308).

De acordo com os comandantes da SADF envolvidos, o ataque a Tumpo falhou devido à capacidade tática dos cubanos. Dois novos ataques a Tumpo (em 29 de fevereiro e 23 de março) falharam novamente devido à defesa eficaz das forças cubanas (HEITMAN, 1990, p. 253). Naquela altura, as tropas de Cuba estacionadas em Angola haviam aumentado para cerca de 55.000. Desses, pelo menos 40.000 estavam posicionados no sul. Graças ao apoio de Cuba, o moral dos angolanos melhorou muito. Apesar do bombardeio diário, eles estavam firmes como atestado por jornalistas que visitaram a região naquele período,

[...] "Trouxemos vocês aqui", disse o oficial do Exército angolano aos repórteres visitantes, "para mostrar que ainda controlamos Cuito Cuanavale." Atrás dele, uma dúzia de projéteis de artilharia sul-africanos explodiam numa nuvem escura e levantavam grandes colunas de fumaça branca no fundo do vale a menos de um quilômetro de distância. [Os angolanos] embora enlameados e com a barba por fazer, pareciam bem alimentados, bem 
equipados e de bom humor. Muitos acenaram com o polegar para cima no carrinho de pessoal dos visitantes. (KNOX, 1988, p. 7, grifo do autor)

Em razão do embargo internacional de armas desde 1977, a força aérea da África do Sul estava completamente superada pelo sofisticado sistema de defesa aérea fornecido pela União Soviética e pelas capacidades de ataque aéreo em campo da FAPLA e da Força Aérea Popular de Angola (FAPA) e, principalmente, pelo poder aéreo projetado pela Fuerza Aérea Revolucionaria de Cuba. Os sulafricanos foram incapazes de manter a supremacia aérea de que desfrutou durante anos; sua perda, por sua vez, provou ser crítica para o resultado da batalha no terreno.

Após o ataque fracassado em 23 de março de 1988, a SADF e a UNITA se retiraram, depois de sofrerem pesadas baixas no assalto. A retirada se deu em uma das áreas mais minadas do mundo. O fogo de artilharia de Cuba e Angola estava aumentando e os ataques aéreos foram intensos. Vários tanques danificados da SADF foram abandonados no campo minado e, subsequentemente, capturados pelos cubanos (SCHOLTZ, 2013, p. 357). Cuito Cuanavale continuou a ser bombardeado pelas SADF a uma distância de 30 a 40 $\mathrm{km}$.

Um dado muito importante para a compreensão dessa história é que não houve batalha real no próprio Cuito Cuanavale. As SADF nunca lançaram um grande ataque à cidade e os defensores cubanos nunca tentaram contra-atacar e expulsar as SADF dos seus arredores (GLEIJESES, 2013, p. 425). Os sul-africanos nunca puderam usar suas pontes flutuantes portáteis, e seus bombardeios constantes com armas de longo alcance não conseguiram desalojar os angolanos e cubanos (BROOKE, 1988, p. 1).

Em 30 de abril de 1988, uma operação defensiva foi montada. A operação Displace foi lançada pela SADF para evitar uma ofensiva das FAPLA durante o mês de maio. O objetivo da operação era cercar a cabeça de ponte com um campo minado para evitar que FAPLA avançasse da margem leste do rio Cuito (HEITMAN, 1990, p. 281). Aviões cubanos e 1.500 soldados do Exército de Cuba estavam reforçando a FAPLA em Cuito Cuanavale. 


\section{Desdobramentos no sul de Angola}

Em 10 de Março de 1988, a defesa de Cuito Cuanavale estava assegurada. Após três ataques fracassados da SADF, as unidades cubanas sob o comando do general Leopoldo Cintra Frias das FAPLA e da SWAPO avançaram de Lubango para sudoeste, iniciando uma ofensiva naquele setor. A primeira resistência sul-africana foi encontrada perto de Calueque em 15 de março, seguida por três meses de duros combates, enquanto os cubanos avançavam em direção à fronteira com a Namíbia. Em um comunicado, as forças militares de Cuba informaram, em meados de março, que "A África do Sul simplesmente teve seus dentes quebrados contra a forte resistência de ferro de Cuito Cuanavale" (BROOKE, 1988, p. 1).

No final de março, os cubanos modernizaram várias pistas de pouso nesta parte de Angola para estender seu poder aéreo ao sudoeste da África. Além disso, um sistema de 150 baterias de mísseis SAM SA-8 foi estabelecido, o que finalmente pôs fim à superioridade aérea sul-africana no sul de Angola (STAPLETON, 2010, p. 184).

O chefe do Estado-Maior sul-africano, general Jannie J. Geldenhuys, anunciou uma retirada tática das tropas do sul de Angola em dezembro; mas em abril admitiu que a retirada foi retardada por considerações estratégicas (BROOKE, 1988, p. 1). Os dias 12 e 21 março de 1988 foram o período mais pesado de batalhas entre o exército sul-africano e o cubano e as tropas angolanas perto Cuito-Cuanavale. Os sul-africanos viram-se obrigados a recuar, devido ao perigo de as suas unidades serem cercadas pelas tropas cubanas que desembarcaram nos portos do sul de Angola (SHUBIN, 2007).

No final de maio, o exército de Cuba tinha duas divisões no sudoeste de Angola. Em 26 de maio de 1988, o chefe da SADF anunciou: "as forças cubanas e SWAPO fortemente armadas, integradas pela primeira vez, moveram-se para o sul dentro de $60 \mathrm{~km}$ da fronteira com a Namíbia" (MWAKIKAGILE, 2015, p. 147). As forças restantes da SADF, em Cuito Cuanavale (imagem 1), estavam em vias de serem encurraladas. No mapa abaixo pode ser visto a localização da cidade e do entorno do espaço em que foi travada a batalha 
Imagem 1 - Mapa de Angola mostrando a posição de Cuito Cuanavale.

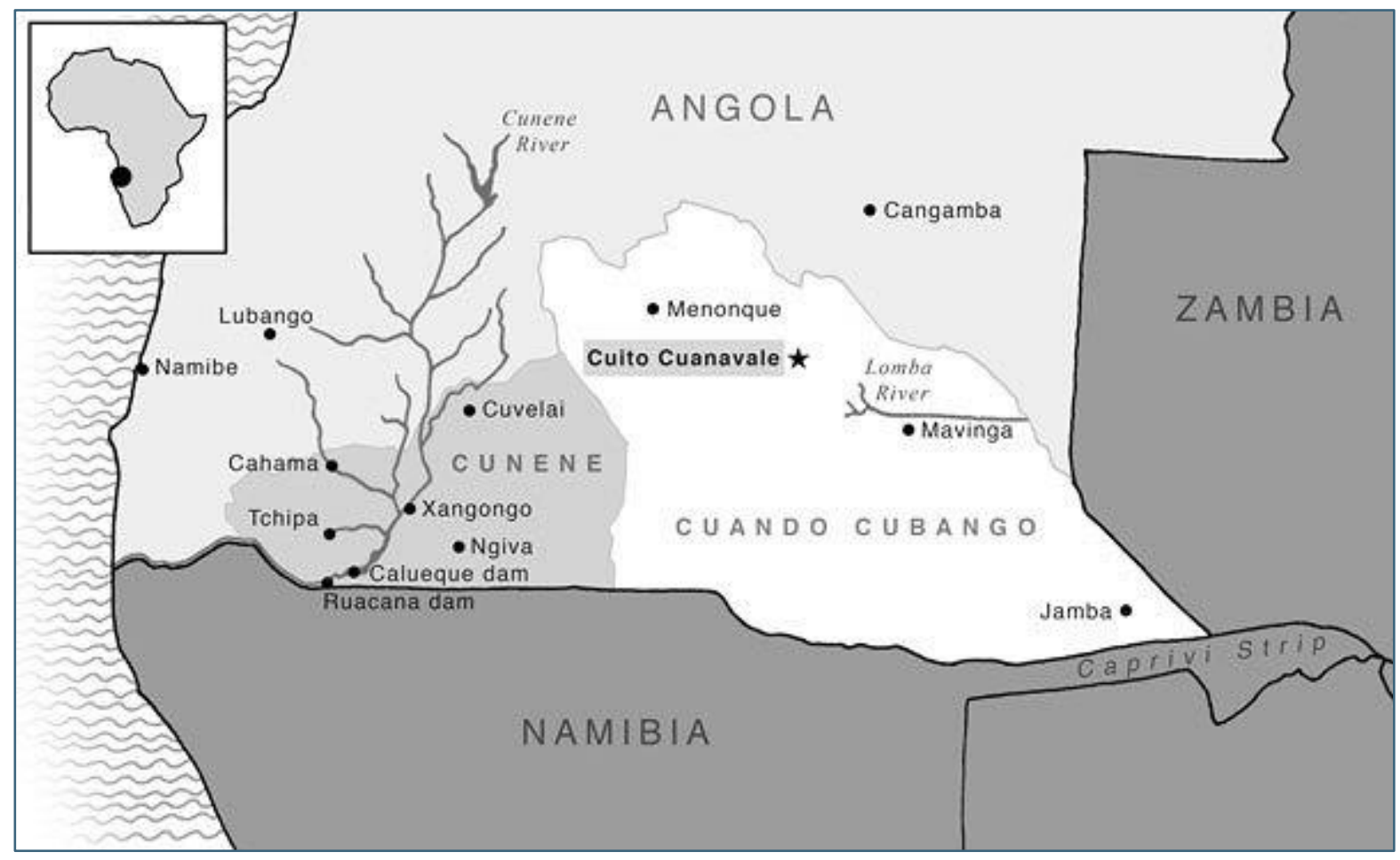

Fonte: KASRILS, Ronnie. Cuito Cuanavale, Angola-25th anniversary of a historic African battle. Monthly Review, New York, v. 64, n. 11, p. 43-51, 2013. Disponível em: http://monthlyreview.org/2013/04/01/cuito-cuanavale-angola/. Acesso em: 15 oct. 2020.

Em junho, as forças cubanas possuíam duas bases aéreas avançadas em Cahama e Xangongo, com as quais o poder aéreo cubano poderia ser projetado para a Namíbia (POLLACK, 2013, p. 226). Todo o sul de Angola já estava coberto pela rede de radar e defesa aérea com mísseis SA-8. Em 8 de Junho de 1988, a SADF convocou 140.000 homens da reserva, dando uma indicação da gravidade da situação (GEORGE, 2005, p. 243-246).

O presidente Fidel Castro, em sua biografia, escrita com Ignacio Ramonet, lembrou que "[...] enquanto as tropas sul-africanas estavam sendo lentamente sangradas em Cuito Cuanavale, no Sudoeste, [...]" (CASTRO; RAMONET, 2006, p. 346). Uma força combinada de "[...] 40.000 soldados cubanos [...] apoiados por cerca de 600 tanques, centenas de peças de artilharia, 1.000 armas antiaéreas e as ousadas unidades de MiG-23 que assumiram os céus avançaram em direção à fronteira com a Namíbia, prontos para varrer as forças sul-africanas" (CASTRO; RAMONET, 2006, p. 346). 
As forças de Cuba mantiveram uma postura exclusivamente defensiva em Cuito Cuanavale, mantendo a SADF fixa no lugar, enquanto realizava sua proposta de longa data de lançar uma manobra de flanco em direção à fronteira do Sudoeste Africano começando com um movimento de tropas cubanas em força divisionária a oeste do rio Cunene, que tinha o potencial de se expandir para uma invasão do Sudoeste da África (SCHOLTZ, 2010, p. 81-97).

Em junho de 1988, os cubanos se prepararam para avançar em Calueque, partindo de Xangongo e Tchipa. Em caso de contra-ataques sul-africanos, Castro deu ordens para se prepararem para destruir os reservatórios e a hidroelétrica de Ruacaná e atacar as bases sul-africanas na Namíbia. A ofensiva começou em Xangongo em 24 de junho colidindo, imediatamente, com a SADF a caminho de Cuamato. Embora as SADF tenham sido expulsas, as FAPLA juntamente com as FAR não os perseguiram e retiraram-se para a sua base. Em 26 de julho de 1989, a SADF bombardeou Tchipa com artilharia de longo alcance e Castro deu ordens para o avanço imediato sobre Calueque e um ataque aéreo contra os acampamentos e instalações militares da SADF em torno de Calueque. ${ }^{6}$

Naquele momento, o comandante geral sul-africano na Namíbia reconheceu, em 26 de junho, que os MiG-23 cubanos estavam voando sobre a Namíbia, se tornando uma reversão completa de tempos anteriores, quando o controle dos céus pertencia à SAAF. Ele acrescentou que "[...] a presença dos cubanos causou uma onda de apreensão" (GLEIJESES, 2007, p. 1), na África do sul.

Após um confronto com um grupo avançado da FAR e das FAPLA, em 27 de junho, as SADF recuaram para Calueque sob o bombardeio de aviões cubanos e cruzaram a fronteira com a Namíbia naquela mesma tarde. Àquela altura, caças MiG-23 cubanos haviam realizado vários ataques às posições da SADF em torno da barragem de Calueque, $11 \mathrm{~km}$ ao norte da fronteira com a Namíbia, danificando também a ponte e as instalações hidrelétricas. A maior força dos cubanos, ainda a caminho, não entrou em ação e voltou para Tchipa. Com a

\footnotetext{
${ }^{6}$ Ver: CASTRO, Fidel. We will transform this setback into a victory. The Militant, [s.l.], v. 53, n. 30, p. 13, 11 Aug. 1989.
} 
retirada da SADF para a Namíbia em 27 de junho, as hostilidades cessaram (GEORGE, 2005. p. 243-246).

Os cubanos, juntamente com as forças angolanas e da SWAPO, avançaram em direção à Namíbia e expuseram a insegurança e vulnerabilidade das tropas sul-africanas no norte do país. Essa vulnerabilidade era tal que um alto oficial sul-africano disse: "Se os cubanos tivessem atacado [a Namíbia], eles teriam invadido o lugar. Não poderíamos tê-los impedido." Isso foi ainda agravado pelos desastres sul-africanos no final de junho de 1988 em Calueque e Tchipia, onde os sul-africanos sofreram sérias derrotas. Segundo Campbel (1990, p. 26), “A morte dos recrutas brancos intensificou a oposição [à guerra] dentro da África do Sul enquanto as famílias começavam a enterrar os jovens que estavam morrendo em uma terra distante."

O jornal sul-africano Weekly Mail classificou a derrota dos sul-africanos como "uma humilhação esmagadora", e afirmou em suas páginas que "o exército mais forte da África não tem superioridade aérea em uma guerra que mais se parece com as trincheiras do Somme do que a mais familiar guerra de contra insurgência dos tempos modernos" (UMA HUMILHAÇÃO..., 1988, p.1). Ainda de acordo com Horace Campbel, as perdas em Angola intensificaram o movimento anti-guerra na África do Sul, com mais de 143 recrutas se recusando a servir na SADF (1990, p. 26).

O New York Times havia também feito referência à batalha e aos sucessos obtidos pelo Ejercito Revolucionario de Cuba e pela FAPLA, em reportagem de capa do dia 18 de maio de 1988. Com a chamada "Angolanos vencendo a África do Sul em uma batalha remota”, o jornalista James Brooke escreveu que:

Os artilheiros sul-africanos disparam apenas 40 projéteis de artilharia por dia contra as ruínas desta cidade agrícola, um sinal para os soldados angolanos e cubanos de que uma batalha crucial pelo futuro da África Austral está a seu favor. Algumas semanas atrás, no auge da batalha, 300 granadas por dia atingiram esta guarnição avançada e sua pista de pouso de 2 quilômetros. (BROOKE, 1988, p. 1)

Os combates em Cuito Cuanavale foram os mais violentos na África desde a Segunda Guerra Mundial. Após o fracasso da ofensiva de março, os sul- 
africanos foram forçados a ir para a mesa de negociação. Como nas discussões de Genebra em 1981, os sul-africanos hesitaram na esperança de usar as negociações para reavaliar suas opções militares (CAMPBELL, 1990, p. 26). A batalha poderia ser classificada como empate, mas na realidade a África do Sul havia perdido (SHUBIN, 2007).

Somente após a batalha de Cuito Cuanavale é que o governo sul-africano do Presidente Peter Botha demonstrou um verdadeiro interesse nas negociações de paz. A estratégia militar cubana no sul de Angola, em 1988, trouxe urgência às negociações. Depois de deter a contraofensiva da SADF em Cuito Cuanavale, e abrir uma segunda frente a oeste, as Fuerzas Armadas Revolucionarias de Cuba estacionadas em Angola inverteram a situação no terreno.

A grande perda de vidas em Calueque gerou indignação na África do Sul. O governo ordenou uma circunscrição imediata. As forças da SADF que permaneceram no leste de Angola foram instruídas para evitar combates e mais baixas. Após os confrontos sangrentos de 27 de junho, as SADF de 13 de julho criaram a 10aㅡ Divisão em defesa do norte da Namíbia, caso as FAR de Cuba tentassem uma invasão à África do Sul (GEORGE, 2005, p. 245).

Durante as negociações realizadas no Cairo, Egito, o chefe da delegação de Cuba Jorge Risquet, respondendo às exigências sul-africanas afirmou que:

Acabou o tempo das suas aventuras militares, dos atos de agressão que praticaram impunemente, dos massacres de refugiados. [Vocês] estão agindo como se fossem um exército vitorioso, ao invés do que realmente são: um agressor derrotado que se retira. [...] a África do Sul deve enfrentar o fato de que não obterá na mesa de negociações o que não conseguiu no campo de batalha. (RISQUET, 1988 apud GLEIJESES, 2007, p. 1)

O Secretário de Estado Adjunto americano para assuntos africanos Chester Crocker, informou ao Secretário de Estado americano, George Shultz, que as conversações estavam ocorrendo,

[...] num contexto de crescente tensão militar em torno do grande aumento de tropas cubanas fortemente armadas no sudoeste de Angola nas proximidades da fronteira com a Namíbia. [...] a concentração de tropas cubanas no sudoeste de Angola criou uma dinâmica militar imprevisível. (CROCKER, 1988 apud GLEIJESES, 2007, p. 1) 
Quando o governo da África do Sul alertou contra uma invasão do Sudoeste da África, Castro respondeu que eles "não estavam em posição de exigir nada” (VANNEMAN, 1990, p. 41-57). Os cubanos estavam em uma situação muito segura, foram a força motriz das negociações na fase final, iniciada em julho de 1988. Os aliados do MPLA queriam manter o status quo após os sucessos no Sul, portanto, tiveram que ser persuadidos a continuar nas negociações.

Preocupado com a escalada da luta no Cunene para uma guerra total, Chester Crocker conseguiu um primeiro avanço em Nova York em 13 de julho. Os cubanos substituíram Jorge Risquet por Carlos Aldana Escalante, que era o chefe de assuntos ideológicos e relações internacionais do Partido Comunista de Cuba, considerado mais propenso à conciliação. Após semanas de negociação um acordo de paz foi assinado em 22 de dezembro de 1988 em Nova York, com os cubanos concordando em retirar-se de Angola e por consequência a África do Sul iria deixar a Namíbia, todo o processo levou este país a se tornar independente.

\section{A disputa de memória e história no campo historiográfico}

O resultado da batalha se tornaria uma das maiores disputas de narrativa travada pelos ex-combatentes da SADF. Memorialistas e historiadores contemporâneos - entre os quais os que defendem a vitória da SADF - atenuam a sua derrota. Por outro lado, outros acreditam que foi um meio termo e entre os defensores da Vitoria do FAPLA e da FAR e o que dela resultou: o fim do Apartheid na África do Sul, a Independência da Namíbia e praticamente o sepultamento da Guerra Fria na África.

Um grande problema gira também em torno da intenção de descrever aquilo que o mestre Michel de Certeau chama de "Um lugar social". (CERTEAU, 2011, p. 47). Então, se direciona o estudo entre a vontade e a disponibilidade de pesquisar o comprometimento com a memória e com a história. ${ }^{7}$ Portanto, pretende-se fazer um balanço superficial da produção sobre a batalha e,

\footnotetext{
7 Para Certeau, a operação histórica se refere à: combinação de um lugar social, determinadas práticas ou procedimentos técnicos e, por fim, à escrita (CERTEAU, 2011).
} 
principalmente, indicar que existe uma forte disputa pela memória travada por memorialistas, militares e por historiadores comprometidos com seus estados e, em essência, a compreensão do sentido maior do embate e do seu legado na atualidade.

Com a permissão e com as devidas desculpas pelas faltas, pode-se, grosso modo, apontar um quadro de pesquisadores na África do Sul, conforme assinala André Wessels (2017), ${ }^{8}$ que se dedicaram a construir uma história da guerra de fronteira entre Angola e África do Sul e que fizeram alusão ao envolvimento de todos os atores: Cuba, União Soviética, SWAPO, UNITA e EUA.

Assim, ao referir-se aos diferentes autores que escrevem uma literatura sobre a Guerra da Fronteira, deve-se levar em conta os "historiadores amadores", os jornalistas que escrevem obras populares para o mercado comercial; frequentemente pessoas com pouca ou nenhuma formação histórica e que não têm qualquer inclinação e nem tempo para fazer pesquisas em arquivos. Muitos são ex-militares sul-africanos, oficiais aposentados da SADF, como os generais Johannes Geldenhuys e Magnus Malan; há também os ex-combatentes cubanos, angolanos e até russos que igualmente produziram suas memórias, mas, há, principalmente, os historiadores profissionais na África do Sul.

Em suas narrativas há uma grande dimensão estratégica, lembrando que o que estava em jogo era o resultado final, muito embora os resultados táticos também sejam claramente favoráveis a Cuba e Angola. A maioria dos memorialistas sul-africanos exercem um esforço tremendo para mostrar que os danos causados pela SADF às forças angolanas foram muito grandes, e que mesmo a intervenção cubana não os havia abalado o suficiente para considerar a batalha como uma derrota.

Um ponto de vista bastante controverso da intervenção de Cuba na guerra em Angola é o trabalho de Edward George, que vê a intervenção cubana como pouco mais do que um projeto de vaidade para Fidel Castro projetado para desviar a atenção dos problemas internos em Cuba e melhorar a sua imagem como o líder do Terceiro Mundo (GEORGE, 2005). Contudo, o autor parece não

\footnotetext{
${ }^{8}$ Sobre uma vasta historiografia a respeito da guerra de fronteiras, ver o estudo de: (WESSELS,
} 2017). 
considerar a possibilidade de que o objetivo da intervenção cubana possa ter sido por razões totalmente altruístas - não apenas para proteger a independência de Angola, mas também para enfraquecer a África do Sul ajudando, assim, o movimento de independência na Namíbia e acelerando o fim do regime do apartheid na própria África do Sul. Todos esses objetivos foram alcançados pela intervenção cubana. Ao contrário do que afirma o autor, portanto, as vitórias cubanas em Angola estiveram muito longe de ser uma aventura irresponsável.

Dentro da conjuntura sul-africana, há pesquisadores que nem consideram o embate como decisivo para algo, muito menos que houve uma batalha decisiva tal como Waterloo ou Stalingrado. Esses pontos de vista seriam uma resposta ao historiador italiano que teve acesso à documentação cubana. Um relato muito melhor da intervenção cubana em Angola pode ser encontrado em Conflicting Missions e Visions of Freedom, ambos de Piero Gleijeses ${ }^{9}$, o qual pesquisou fontes de arquivo, particularmente dos Estados Unidos, África do Sul e de Cuba para fornecer uma história internacional sem precedentes deste importante teatro do final da Guerra Fria.

Todas essas fontes apontam para uma conclusão: ao humilhar os Estados Unidos e desafiar a União Soviética, Fidel Castro mudou o curso da história no sul da África. Foi a vitória de Cuba em Angola em 1988 que forçou Pretória a Libertar a Namíbia e ajudou a quebrar o apartheid na África do Sul. Nas palavras de Nelson Mandela, os cubanos "destruíram o mito da invencibilidade do opressor branco [e] inspiraram as massas combativas da África do Sul" (GLEIJESES, 2013, p.426).

Há também uma questão de relevância quando consideramos a perspectiva cubana que, de certa forma, robustece a posição do historiador italiano radicado nos EUA, Pierro Gleijeses, que é a falta de acesso do público a documentos de arquivos cubanos. Tanto quanto é possível situar, Pierro Gleijeses é o único historiador que teve o privilégio de ter acesso a uma série limitada de

\footnotetext{
${ }^{9}$ GLEIJESES, Piero. Conflicting missions: Havana, Washington and Africa, 1959-1976. Chapel Hill: North Carolina University Press, 2002. GLEIJESES, Piero. Visions of freedom: Havana, Washington, Pretoria, and the Struggle for Southern Africa, 1976-1991. Chapel Hill: University of North Carolina Press, 2013.
} 
arquivos de Cuba, cujo acesso foi facilitado por Jorge Risquet, que como um ativo membro do governo de Cuba, e tendo ele mesmo participado das negociações do pós-batalha, também se tornou uma das maiores autoridades sobre a história do envolvimento de Cuba na intervenção em Angola. ${ }^{10}$

Embora Gleijeses não tenha escrito na mesma profundidade sobre a "batalha de Cuito Cuanavale" como tem feito sobre as políticas de Cuba e intervenções na África, ele fornece uma versão sólida e detalhada da intervenção de Cuba durante a Operação Savannah da SADF em Angola, ocorrida em 1975. Isso possibilita ao leitor um vislumbre dos arquivos cubanos, embora seja uma narrativa fortemente pró-cubana. Essa inclinação é demonstrada amplamente pela ausência de qualquer reconhecimento de resultados negativos ou de fatores combinados na experiência da intervenção cubana. Para Castro e Risquet, os cubanos estavam dispostos a lutar e ficaram felizes em ajudar os africanos com motivação e sacrifício. (GLEIJESES, 2013)

Todos esses objetivos foram alcançados pela intervenção cubana. Essas são constatações igualmente observadas nos estudos de Issac Saney, historiador de Trinidad e Tobago, radicado nos EUA. Para ele, que é autor da tese From Soweto To Cuito Cuanavale: Cuba, the War in Angola and the End of Apartheid. (2014), a ajuda cubana é retratada como um ato de altruísmo excepcional, sem qualquer expectativa de reciprocidade, obrigação de dívida ou reembolso sob qualquer forma. A perspectiva angolana de Castro é mesmo intitulada como "pagando nossa dívida para com a humanidade", (SANEY, 2014, p. 70) sublinhando as afirmações de que, ao contrário do neocolonialismo das potências ocidentais, Cuba não pediu nem ganhou nada em estender sua mão à África.

Igualmente, Cuba pode não ter ganhado economicamente de forma mensurável, mas estava construindo relações que seriam úteis para sua futura sobrevivência internacional. A esse respeito, a visão enfática de Isaac Saney de que Cuba não estava agindo como um representante soviético pode ser vista como esclarecedora sobre a construção de sua participação no conserto das

10 Ver: RISQUET VALDÉS, Jorge. Angola: el camino hacia la victoria. Temas, [s.l.], v. 37/38, p. 159167, abr. 2004. 
relações internacionais (SANEY, 2006). Saney mostra isso oferecendo várias fontes e complementa, assim, a visão de Piero Gleijeses.

A experiência cubana é retratada na visão positiva da vitória pelos cubanos e pelos angolanos e corroborada por Rúben G. Jiménez Gómez, um dos combatentes cubanos em Angola, que lutou entre 1987 e 1990, e relatou que:

[...] o desfecho da Batalha do Cuito Cuanavale deu a possibilidade, não só de Angola desfrutar a paz e consolidar a sua própria soberania, mas também permitiu aos combatentes namibianos alcançarem os objetivos a que se debatiam. A independência serviu de inspiração ao povo combatente da África do Sul: o Cuito Cuanavale marcou a viragem na luta para libertar o continente africano [...] do flagelo do apartheid. (GÓMEZ, 2014, p. 134)

Um dos raros livros que trata sobre a campanha aérea cubana em Angola, a partir do ponto de vista dos pilotos de caça foi Trueno justiceiro, escrito por Humberto Trujillo Hernández, cuja narrativa leva em consideração a história dos pilotos cubanos, incluindo as referências à batalha de Cuito Cuanavale, em razão do desfecho da campanha aérea ter sido decisivo pela perda do poder aéreo sulafricano (HERNÁNDEZ, 2005). A experiencia vista a partir de oficiais do exército cubano também foi retratada em Cuatrocientos Noventaitres Dias En Cuito Cuanavale, escrito por Venancio Avila Guerreiro e Eduardo Taurinan Yanez; ambos estiveram em Cuito Cuanavale, no comando do 71 Grupo Tactico das FAR.

A visão dos russos pode ser traduzida na pesquisa dos historiadores Gennady Shubin e Andrei Tokarev, que organizaram e publicaram como livro a narrativa das memórias dos soldados russos que tomaram parte na batalha. Gennady Shubin é Pesquisador Sênior do Instituto Africano da Academia Russa de Ciências em Moscou. É coautor e publicou vários livros, nomeadamente sobre a história da África do Sul, a Guerra Anglo Boer (1899-1902) e várias memórias da Guerra Angolana (1966-1989). De todas as publicações anteriores, esta é apenas a segunda das suas seis sobre a Guerra de Angola. O primeiro livro sobre a memória dos ex-combatentes russos foi: The oral history of forgotten wars: The Memoirs of Veterans of the War, de 2007. O texto trata sobre os depoimentos de dois oficiais conselheiros que participaram tanto da ofensiva Saudando Outubro e que, posteriormente, estiveram em Cuito Cuanavale durante o assédio. 
Andrei Tokarev é chefe do Centro de Estudos Sul-africanos no Instituto Africano em Moscou e professor associado na Universidade Militar de Moscou. É um experiente pesquisador sobre os desdobramentos da guerra em Angola durante a década de 1970. Em resposta ao grande número de publicações de autores sul-africanos que participaram na Guerra da Fronteira, publicaram, Bush war: the road to Cuito Cuanavale. Este livro propõe-se a oferecer um vislumbre detalhado das experiências de um dos lados opostos que participaram da guerra. A contribuição em análise consiste em compilações de vários conselheiros soviéticos do Exército angolano.

A publicação apresenta uma lista dos principais armamentos e equipamentos usados e as chamadas "correções" nas perdas, especialmente no resultado da guerra, que por vezes é chamada de impasse militar. As várias imagens do livro e sua abordagem de contar histórias visam levar o leitor a uma busca vívida, a fim de reviver as experiências e nostalgia dos soldados soviéticos durante aquele período (SHUBIN; TOKAREV, 2011).

Uma das maiores discussões no campo militar também gira em torno da ideia de que a batalha é tida como taticamente inconclusiva, e que ambos os lados declararam vitória. Embora seja realmente muito difícil crer que a África do Sul tenha logrado qualquer êxito, taticamente não atingiram os seus objetivos, sendo o fracasso de seu sexto ataque o ponto virada da batalha e, na iminência de serem derrotados, recuaram para não serem envolvidos e, provavelmente, destruídos pelo exército de Cuba após retomar a iniciativa no Sudoeste, em Cunene.

A UNITA e seus aliados sul-africanos declararam vitória porque, em seu julgamento, a ofensiva inicial das FAPLA foi estilhaçada e as brigadas inimigas participantes sofreram perdas imensas que não puderam ser facilmente substituídas; mas, essa resposta à ofensiva inicial das FAPLA e ao seu fracasso não determinou o resultado final, muito pelo contrário.

A FAPLA e o Exército de Cuba puderam declarar vitória porque foram capazes de manter suas defesas em torno do Cuito Cuanavale. Além de que a reação de ambas as forças, inclusive em outras frentes, empurrou a UNITA e as tropas sul-africanas a um recuo rápido de volta ao seu território à Namíbia e à 
África do Sul. O presidente Fidel Castro poderia inclusive ter ordenado uma operação de invasão à Namíbia e mesmo à África do Sul, mas não o fez.

Em sua biografia, coescrita com Ignacio Ramonet, Fidel Castro afirmou, que a África do Sul sofreu um revés catastrófico como resultado da batalha porque,

A esmagadora vitória em Cuito Cuanavale, e especialmente o avanço fulminante da poderosa frente de tropas cubanas no sudoeste de Angola, pôs fim à agressão militar contra aquele país. O inimigo teve que engolir sua arrogância de sempre e se sentar à mesa de negociações. (CASTRO; RAMONET, 2006, p. 330)

Essa derrota forçou a África do Sul a seguir para a mesa de negociações, o que acabou resultando na independência da Namíbia e acelerando dramaticamente o fim do apartheid. O equilíbrio de poder regional foi transformado fundamentalmente. Victoria Brittan observou que Cuito Cuanavale se tornou "um símbolo em todo o continente de que o apartheid e seu exército não eram mais invencíveis" (BRITTAIN, 1998). Segundo ela, a batalha de Cuito Cuanavale representará para sempre as dimensões mais controversas da guerra em Angola.

Em visita a Cuba, Nelson Mandela disse ao povo cubano que o sucesso das FAPLA e da FAR na batalha de Cuito Cuanavale foi "[...] um ponto de viragem para a libertação do nosso continente e do meu povo" (CASTRO; MANDELA, 1991, p. 23), bem como a luta pela independência da Namíbia. Por sua vez, Fidel Castro igualmente declarou que a batalha foi um ponto de inflexão: "A partir de agora a história da África terá para ser escrito antes e depois de Cuito Cuanavale." (CASTRO, 1991, apud SHUBIN, 2008, p. 105)

As fontes referentes à batalha ainda não se encontram plenamente disponíveis, mas um detalhe muito relevante é que os estudos produzidos pelos sul-africanos alegam que estes são frutos de uma documentação disponibilizada. Dentro desse argumento, vale lembrar que qualquer intencionalidade em produzir algo em torno de uma suposta verdade de quem perdeu já torna o estudo bastante discutível. Em uma operação historiográfica, é possível explorar as fontes para qualquer sentido, da crítica à afirmação positiva. É obvio que os estudos sul-africanos comprometidos em exaltar a memória de seus 
combatentes tenderá a exaltar a campanha; talvez até criticar, mas jamais admitir a derrota.

A narrativa da batalha parece ter conquistado apreço mesmo no mundo acadêmico, cuja preocupação em exaltar a memória dos sul-africanos persiste. Assim é o estudo de Janet Szabo, cuja dissertação procura trabalhar a ideia de um impasse que teria sido resolvido pela opção de negociação, e que os sulafricanos irremediavelmente iriam continuar a infligir perdas terríveis ao FAR e FAPLA caso não negociassem (SZABO, 2019). A pesquisadora alega que o seu estudo parte de uma documentação sul africana recém-disponibilizada junto aos arquivos do país.

Dentre os historiadores acadêmicos mais representativos, é possível destacar Leopold Scholtz, que produziu um dos estudos mais importantes sobre a Guerra da Fronteira intitulado: The SADF in the Border War 1966-1989 (SCHOLTZ, 2013). Suas pesquisas fornecem visões gerais da guerra como um todo. Em uma linha semelhante, encontra-se o trabalho de Gary Baines, que pode ser considerado um dos mais importantes historiadores da guerra na África do Sul por ter produzido um importante trabalho sobre o conflito, em particular sobre o seu o rescaldo e sobre as consequências que esta teve para aqueles que estavam envolvidos.

Gary Baines publicou um livro intitulado: South Africa's "Border War": Contested narratives and conflicting memories. Em seu texto, o tema das memórias conflitantes a respeito de toda a Guerra de Fronteira é o cerne da pesquisa. O livro é composto por uma série de ensaios sobre os embates envolvendo Angola, UNITA e África do Sul. Muitos desses ensaios são dedicados a materiais que não são inteiramente relevantes para este estudo. Baines ganha relevância no capítulo que trata da "Batalha de Cuito Cuanavale" (BAINES, 2015).

Nesse trabalho, ele se propõe a adotar uma abordagem equilibrada para dissipar mitos de ambos os lados que cercam o período estudado, introduzindo o conceito de uma abordagem "centrada na batalha". Enquanto outros autores concentram-se mais em narrativas partidárias, nacionalistas do ANC e cubanas, o autor procura reverter mitos que são aplicáveis a todos os lados deste "debate", como praticamente todos os comentadores são culpados de reduzir o balanço 
do conflito angolano a tão somente a questão militar. Baines não faz concessões, ao mesmo tempo em que é muito crítico.

O autor também adota uma visão cada vez mais associada a autores e historiadores contemporâneos de que a "Guerra da Fronteira" angolana não foi uma guerra de "vencedores ou vencidos", mas sim aquela que se resolveu na base da concessão. O autor enfatiza os eventos geopolíticos mais decisivos que foram desdobrados posteriormente, para argumentar que têm pouca base para reivindicar um resultado vitorioso (BAINES, 2015). Assim, seu trabalho fornece uma importante abordagem imparcial em um campo de interpretação que há muito foi altamente polarizado. Novamente, tal como Scholtz, as narrativas contestadas de Baines serão essenciais para todas as pesquisas futuras sobre a guerra da fronteira angolana. O autor relata os lados da história da SADF e SWAPO e mostra como e por que a controvérsia continua.

Como Gary Baines aponta no capítulo seis, intitulado: "The Battle of Cuito Cuanavale Successful Stalemate and Vicarious Victory” de seu livro South Africa's "Border War", ele afirma que, como acontece com muitos outros conflitos, podese ganhar uma guerra, mas pode-se perder a batalha da memória e vice-versa (BAINES, 2015). Sua visão acabou recebendo críticas de colegas. Christo Doherty escreveu uma resenha para o seu livro "Border War", na qual fez algumas observações sobre as opiniões e conclusões de Baines expressas nos capítulos cinco e seis (DOHERTY, 2016).

O estudo de Christian Williams segue nessa mesma linha, na qual é também expressa que há uma batalha pela verdade sobre a série de combates que ocorreram ao longo do rio Lomba, incluindo os que ocorreram nas proximidades de Cuito Cuanavale (WILLIAMS, 2015). Por outro lado, historiadores exaltadores da vitória da SADF, como Stephen Beck, insistem em afirmar que provavelmente é muito mais fácil acreditar nos relatórios de inteligência da SADF, que faziam um julgamento muito negativo da capacidade dos combatentes das FAR de Cuba, ao afirmar que chegaram em Angola cada vez mais desiludidos e acabaram enfrentando uma experiência semelhante ao cinismo e cansaço dos soldados americanos que lutaram no vietnã (BECK, 2018, p. 19). 
Em uma outra perspectiva (menos belicista), há o trabalho de Andreas Velthuizen. Segundo ele, após o encerramento da batalha por Cuito Cuanavale, a nova fase que viria e as consequências dela não eram claras, mas logo ficou evidente que o uso da força militar culminou em um resultado oposto ao esperado para todos os atores envolvidos. Velthuizen, portanto, é um historiador mais preocupado com os efeitos positivos da diplomacia e da paz.

Para ele, as SADF não conseguiram capturar Cuito Cuanavale, e simultaneamente ocorreu uma luta contra as forças cubanas na província de Cunene sem perda inaceitável de vidas e custos elevados. A União Soviética e Cuba, os patrocinadores da Angola e SWAPO acordaram com os EUA que o conflito militar devia terminar no interesse de uma paz mundial mais ampla. Portanto, era fútil para qualquer um continuar a guerra nesse nível. Era chegada a hora, então, de empregar as opções diplomáticas e políticas para uma solução pacífica, apesar do risco de um conflito de guerrilha de baixa escala contínuo em Angola e Namíbia (VELTHUIZEN, 2009, p. 117).

Fora da África e do mundo dos contendores, estudos provenientes de outros países começaram a ser produzidos por especialistas, sobretudo por historiadores acadêmicos. Entre os anos de 1990 até os dias atuais, em alguns desses estudos ressalta-se a importância dos diferentes atores como construtores de um processo, uma vez que foi durante essa batalha que a participação cubana demonstrou ser fundamental no apoio às forças angolanas no combate à SADF. Essa é a posição do historiador Canadense Timothy Stapleton (2010), um especialista em história militar da África e muito particularmente da África do Sul.

Para Stapleton, a SADF havia conduzido muitas operações transfronteiriças bem-sucedidas contra o comando e a logística da PLAN e ganhou batalhas convencionais, como no rio Lomba, onde salvou a UNITA ao frustrar uma ofensiva planejada pelas FAPLA e pelos soviéticos. De acordo com o autor, é muito difícil afirmar que os sul-africanos conseguiram uma vitória em Cuito Cuanavale, pois seus objetivos não eram claros e não conseguiram expulsar as unidades das 
FAPLA/FAR a oeste do Rio Cuito ${ }^{11}$, ao contrário da FAPLA e da FAR, que tinham um objetivo bem definido que era manter Cuito Cuanavale e o fizeram, apesar das perdas massivas (STAPLETON, 2010, p. 186).

O avanço das FAPLA e FAR na província de Cunene foi mais importante para motivar a retirada da África do Sul de Angola e trazer um acordo internacional. Segundo Stapleton, ao se focar em quem ganhou e perdeu os combates específicos, corre-se o risco de perder de vista o panorama geral. Os sul-africanos intervieram em Angola por causa da insurgência ao sul da fronteira. Contudo, a SWAPO/PLAN - devido a uma mistura de fatores políticos e militares - finalmente haviam atingido o seu objetivo de longo prazo: a independência da Namíbia (2010, p. 186).

Para o historiador norte americano, Dennis Laumann, o exército do apartheid da África do Sul foi de fato derrotado por uma aliança pan-africanista que incluía dezenas de milhares de voluntários cubanos. Sua vitória forçou os governantes racistas da África do Sul a entrarem em negociações que levaram ao fim da perseguição às organizações antiapartheid, à libertação de Nelson Mandela, à independência da Namíbia e, finalmente, à liberdade para a África do Sul (LAUMANN, 2012). Muito embora as narrativas históricas prevalecentes sobre o fim do apartheid ignorem o significado épico desta batalha, ela havia de fato mudado os rumos da África Austral.

\section{Conclusão}

Há quem defenda que a batalha de Cuito Cuanavale foi uma vitória de Pirro para ambas as partes: Angola e Cuba sofreram grandes perdas em termos de pessoal e material, enquanto a África do Sul e a UNITA não conseguiram ganhar terreno. Já que Angola e Cuba tinham como objetivo estratégico segurar a cidade, enquanto o objetivo sul-africano era capturá-la, ${ }^{12}$ pode-se falar em vitória angolano-cubana.

\footnotetext{
${ }^{11}$ Essas considerações são tomadas a partir de uma percepção que provavelmente a SADF nunca tivesse a intenção de tomar o Cuito Cuanavale, como alegam.

12 O general Magnus Malan, na época ministro da defesa da África do Sul, negou que pretendiam tomar a cidade. Os historiadores ligados à construção de uma memória positiva da SADF defendem a mesma tese de que esse não era o objetivo dos sul-africanos.
} 
A vitória das tropas cubano-angolanas deixou claro para a África do Sul que uma invasão militar do país por esses estados caminhava para um cenário real. Isso tinha que ser evitado a todo custo porque na África do Sul, como no Zimbábue, temia-se que a minoria branca fosse permanentemente e completamente removida do poder.

Naquela época, os centros políticos em Washington e Moscou eram de opinião que um confronto direto entre os dois grandes blocos de poder não fazia sentido, porque a importância global da África Austral não era grande o suficiente para ambos os lados. Sob o governo de Mikhail Gorbatchev, a compreensão que se desenvolveu por muito tempo veio à tona; de que a política soviética para a África deveria ser totalmente reconsiderada. O custo do apoio sustentado para levantes revolucionários foi estimado como muito alto, razão pela qual a divergente política interna e externa foi cada vez mais suportada pelos países aliados da União Soviética na África.

O envolvimento militar soviético em Angola, que é comparativamente elevado em relação a outras regiões de conflito africanas, aparentemente contradizia a política de Gorbachev para a África. Mas os analistas de Moscou viram no envolvimento dos EUA com a UNITA a tendência para uma política global de retrocesso dos norte-americanos perpetrada pela administração do presidente Ronald Reagan, cujo resultado na África poderia ter sido diferente, e derrubado o governo do MPLA em Luanda. A fim de defender a reivindicação de um aliado e afrontar uma potência militar global equivalente, a União Soviética forneceu ampla assistência militar ao governo de Angola.

O lugar de convergência das diferenças, entre as superpotências e países da África Austral seria em Cuito Cuanavale, onde também ocorreria a última batalha da Guerra Fria e seria o lugar de autoafirmação de Cuba como um Estado soberano que podia decidir sobre seus rumos e marcar seu espaço de forma autônoma no cenário internacional.

Cuito Cuanavale foi o local de uma batalha travada entre forças cubanas, angolanas, namibianas e sul-africanas. Durou de agosto de 1987 a março de 1988 e foi a maior batalha travada em solo africano desde a Segunda Guerra Mundial. Em seu curso, pouco menos de 8.000 soldados foram mortos, mas o seu 
resultado político trouxe um legado de mudança que reverbera até hoje e continuará mais além, como símbolo da derrota ao apartheid.

\section{Referências}

BAINES, Gary. South Africa's “Border War”: contested narratives and conflicting memories. London: Bloomsburg Academic, 2015.

BECK, Stephen. Contested historical interpretations and the narrative of the Angolan-South Africa War 1987-1988: a military outcome? January 2018. Thesis (Master in History) - Univeristy of Stellenbosch, Stellenbosch, Western Cape, 2018.

BERNARDINO, Luís. A Posição de Angola na arquitectura de paz e segurança africana. Lisboa: Edições Almedina, 2013.

BREYTENBACH, Jan. Buffalo Soldiers: The Story of South Africa's 32. Battalion 1975-1993. Alberton: Galago Publishing, 2002.

BRITTAIN, Victoria. Death of dignity: Angola's civil war. London: Pluto Press, 1998.

BROOKE, James. Angolanos vencendo a África do Sul em uma batalha Remota, Seção A, p. 1, The New York Times, May 18, 1988.

CAMPBELL, Horace. The siege of Cuito Cuanavale, Current African Issues, Uppsala, n. 10, Nordiska afrikainstitutet, p. 1-30, 1990.

CASTRO, Fidel; MANDELA, Nelson. How Far We Slaves Have Come: South Africa and Cuba in today's world. New York: Pathfinder, 1991.

CASTRO, Fidel; RAMONET, Ignacio. My Life: a spoken autobiography. New York: Scribne, 2006.

CERTEAU, Michel de. A escrita da história. 3. ed. Rio de Janeiro: Forense Universitária, 2011.

DOHERTY, Christo. Review article of G. Baines, South Africa's "Border War": contested narratives and conflicting memories (Bloomsbury Academic, London, 2015). Journal for Contemporary History, Centurion, v. 41, n. 2, p. 273-281, 2016. 
GEORGE, Edward. The Cuban intervention in Angola, 1965-1991. London: Frank Cass, 2005.

GLEIJESES, Piero. Cuito Cuanavale revisitada. Weekly Mail, [s.l.], p. 1, 9 July 2007.

GLEIJESES, Piero. Visions of freedom: Havana, Washington, Pretoria, and the struggle for Southern Africa, 1976-1991. Chapel Hill: University of North Carolina Press, 2013.

GÓMEZ, Rubén G. Jiménez. Cuito Cuanavale: crónica de uma Batalha, Luanda: Mayamba Editora, 2014.

GUERRERO, Venancio Avila; YANEZ, Eduardo Taurinan. Cuatrocientos noventaitres dias en Cuito Cuanavale. Habana: Casa Editorial Verde Olivo, 2014.

HEITMAN, Helmoed-Römer. War in Angola: the final South African phase. Gibraltar: Ashanti, 1990.

HERNÁNDEZ, Humberto Trujillo. Trueno justiceiro: mis campañas en cielo angolano. Habana: Ediciones Verde Olivo, 2005.

KASRILS, Ronnie. Cuito Cuanavale, Angola -25th anniversary of a historic African battle. Monthly Review, New York, v. 64, n. 11, p. 43-51, 2013. Disponivel em: http://monthlyreview.org/2013/04/01/cuito-cuanavale-angola/. Acesso em: 15 out. 2020

KNOX, Margaret. Batalha por uma pequena cidade 'no fim da terra'. The Washington Post, Washington, p. 7, 1 Mar. 1988.

LAUMANN, Dennis. African world histories: colonial Africa, 1884-1994. New York: Oxford University Press, 2012.

MWAKIKAGILE, Godfrey. Namibia: conquest to independence: formation of a nation. Dar es Salaam: New Africa Press, 2015.

POLLACK, Peter. The last hot battle of the cold war, decision at Cuito Cuanavale and the battle for Angola, 1987-1988. Oxford: Casemate, 2013.

SANEY, Isaac Henry. From Soweto To Cuito Cuanavale: Cuba, the War in Angola and the End of Apartheid. 2014. Thesis (PhD in History) - Department of History School of Oriental and African Studies University of London, London, 2014. 
SCHOLTZ, Leopold. The South African Strategic and Operational Objectives in Angola, 1987-88. Scientia Militaria, South African Journal of Military Studies, Saldanha, v. 38, n. 1, p. 68-98, 2010.

SCHOLTZ, Leopold. The SADF in the border war 1966-1989. Cape Town: Tafelberg, 2013.

SHUBIN, Gennady; TOKAREV, Andrei (eds.). Bush war: the road to Cuito Cuanavale. Soviet soldiers' accounts of the Angolan war. Johannesburg: Jacana, 2011.

SHUBIN, Gennady. The oral history of forgotten wars: the memoirs of veterans of the war. Moscow: Memories, 2007.

SHUBIN, Vladimir The hot Cold War: the USSR in Southern Africa. Londres: Pluto Press, 2008.

SPIES, Francois J.du Toit. Operasie Savannah: Angola 1975-1976. Pretoria: S.A. Weermag, 1989.

SOUTH AFRICA. Report of the truth and reconciliation commission. [S.l.: s.n.], 1998. v. 2. Disponível

em: http://www.doj.gov.za/trc/report/finalreport/TRC\%20VOLUME\%202.pdf. Acesso em: 10 set. 2020.

STAPLETON. Timothy J. A military history of South Africa: from the Dutch-Khoi wars to the end of Apartheid. California: ABC-CLIO LLC., 2010.

SZABO, Janet. Was there really a Battle of Cuito Cuanavale? An evaluation of conflicting narratives based on original SADF documents. September 2017. Thesis (Master in Air Power in the Modern World) - Department of War Studies, Faculty of Social Sciences and Public Policy, King's College, London, 2017.

UMA HUMILHAÇÃO esmagadora. Weekly Mail, [s.l.], p.1, July l, 1988.

VANNEMAN, Peter. Soviet foreign policy for Angola/Namibia in the 1980s: a strategy of coercive diplomacy. In: KAHN, Owen Ellison (ed.). Disengagement from Southwest Africa: the prospects for peace in Angola and Namibia. New Brunswick: University of Miami Institute for Soviet and East European Studies, 1990. p. 69-94.

VANNEMAN, Peter. Soviet Strategy in Southern Africa: Gorbachev's pragmatic approach. Stanford: Hoover Institution Press, 1990 
VELTHUIZEN, Andreas. The significance of the battle for Cuito Cuanavale: longterm foresight of the current strategic landscape. Scientia Militaria, South African Journal of Military Studies, Saldanha, v. 37, n. 2, p. 107-123, 2009.

WESSELS, André. Half a century of south african "border war" literature: a historiographical exploration. Journal for Contemporary History, Centurion, v.42, n. 2, p. 24-47, 2017.

WILLIAMS, Christian A. National liberation in postcolonial Southern Africa: a historical ethnology of SWAPO's exile camps. New York: Cambridge University Press, 2015. 